Cite this: Dalton Trans., 2014, 43 , 5713

Received 22nd November 2013, Accepted 7th January 2014

DOI: $10.1039 / \mathrm{c} 3 \mathrm{dt} 53305 \mathrm{k}$

www.rsc.org/dalton

\section{Probing the highly efficient room temperature ammonia gas sensing properties of a luminescent ZnO nanowire array prepared via an AAO-assisted template route}

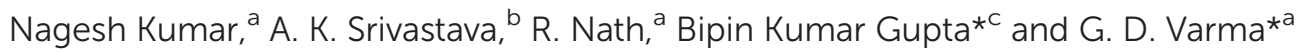 \\ Here, we report the facile synthesis of a highly ordered luminescent $\mathrm{ZnO}$ nanowire array using a low \\ temperature anodic aluminium oxide (AAO) template route which can be economically produced in large \\ scale quantity. The as-synthesized nanowires have diameters ranging from 60 to $70 \mathrm{~nm}$ and length \\ $\sim 11 \mu \mathrm{m}$. The photoluminescence spectrum reveals that the AAO/ZnO assembly has a strong green \\ emission peak at $490 \mathrm{~nm}$ upon excitation at a wavelength of $406 \mathrm{~nm}$. Furthermore, the $\mathrm{ZnO}$ nanowire \\ array-based gas sensor has been fabricated by a simple micromechanical technique and its $\mathrm{NH}_{3}$ gas \\ sensing properties have been explored thoroughly. The fabricated gas sensor exhibits excellent sensitivity

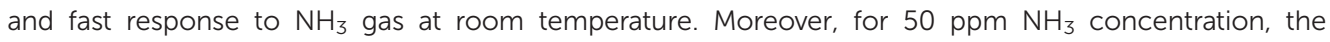 \\ observed value of sensitivity is around $68 \%$, while the response and recovery times are 28 and \\ 29 seconds, respectively. The present synthesis technique to produce a highly ordered ZnO nanowire \\ array and a fabricated gas sensor has great potential to push the low cost gas sensing nanotechnology.
}

\section{Introduction}

Among all the nanoscale materials, metal oxide nanostructures have been extensively studied because of their potential applications in various technological areas, such as electronics, lasers, electron-field emitters, optoelectronics, biological and chemical sensors, logic devices, nanoscale memory, coating systems, superconductivity and catalysis. ${ }^{1-10}$ Recently, many research groups have extensively investigated the various properties of metal oxide nanostructures with different dimensions $(D)$ and they observed that only few of these metal oxide possess either $\mathrm{d}^{0}\left(\mathrm{TiO}_{2}, \mathrm{WO}_{3}, \mathrm{Sc}_{2} \mathrm{O}_{3}, \mathrm{~V}_{2} \mathrm{O}_{5}, \mathrm{CrO}_{3}\right.$ as well as perovskites structures $\left(\mathrm{ScTiO}_{3}, \mathrm{LiNbO}_{3}\right)$ or d $\mathrm{d}^{10}\left(\mathrm{ZnO}, \mathrm{SnO}_{2}, \mathrm{Cu}_{2} \mathrm{O}, \mathrm{In}_{2} \mathrm{O}_{3}\right)$ electronic configuration of cations exhibit feasible gas sensing properties. ${ }^{11}$ Although there exist a few metal oxides with a $\mathrm{d}^{n}$ $(0<n<10)$ configuration of cations $\left(\mathrm{NiO}, \mathrm{VO}_{2}, \mathrm{Cr}_{2} \mathrm{O}_{3}, \mathrm{RuO}_{2}\right.$ etc. $)$ which are sensitive to the environment in their vicinity, these are structurally unstable as they are influenced by oxidation or reduction processes. ${ }^{12}$ Amid the metal oxide nanostructures, $\mathrm{ZnO}$ is one of the most studied semiconducting materials.

\footnotetext{
${ }^{a}$ Department of Physics and Centre of Nanotechnology, Indian Institute of Technology Roorkee, Roorkee-247667, India

${ }^{b}$ Indus Synchrotrons Utilization Division, Raja Ramanna Centre for Advanced Technology, Indore-452013, India

${ }^{c}$ National Physical Laboratory (CSIR), Dr K S Krishnan Road, New Delhi 110012, India.E-mail: gdvarfph@iitr.ernet.in, bipinbhu@yahoo.com; Fax:+91 1332273560
}

It possesses thermodynamically highly stable wurtzite (hexagonal close packed) crystal structure in which the lattice constant ratio $c / a \sim 1.60$ slightly deviates from the ideal value of the hexagonal cell $c / a=1.633$ due to differences between the electronegativity values of $\mathrm{Zn}^{2+}$ and $\mathrm{O}^{2-}$ ions. $\mathrm{ZnO}$ exhibits almost all the unique properties required to make it a feasible gas sensor such as moderate direct band gap (3.37 eV), high mobility of conduction electrons, better chemical and thermal stability under ambient conditions and good activity in redox reactions. $^{13,14}$ Thus 0D, 1D, 2D and 3D nanostructures of $\mathrm{ZnO}$ have been extensively studied worldwide to utilize their excellent gas sensing properties in the fabrication of improved gas sensing devices at low cost. Moreover, the longer dimensions of $1 \mathrm{D} \mathrm{ZnO}$ nanostructures (nanotubes, nanowires and nanorods) make them suitable to connect with the macroscopic world for electrical and many other physical measurements. Therefore, 1D nanostructures are more appropriate for the fabrication of nanoelectronic devices like gas sensors, electronfield emitters, logic devices etc.

In recent times, many research groups have demonstrated the excellent sensitivity, response and recovery characteristics of zinc oxide gas sensors fabricated with individual nanostructures (tubes, wires and rods). ${ }^{15-17}$ However, the large-scale fabrication process of these sensors still suffers from the intrinsic drawback of processing an individual nanostructure. To address this issue, we proposed an alternative route to minimize such drawbacks through a highly ordered template 
based aligned luminescent $\mathrm{ZnO}$ nanowire array. In order to control the material properties and develop functional devices, it is necessary to synthesize nanostructures with a high degree of regularity and alignment at low cost. In general, most of the reported $\mathrm{ZnO}$ nanostructures with different diameters and lengths are synthesized by various methods like solid-liquidvapor processes, metal-organic chemical vapor deposition, pulsed laser deposition, wet chemical methods and templateassisted methods. ${ }^{18-22}$ Recently, the AAO-template route has been the most impressive way because of its low growth temperature and good potential for large scale synthesis of ordered nanostructures. $^{23-28}$

The photoluminescent properties of $\mathrm{ZnO}$ have received much attention because of the ability to tune the optical properties of ZnO by tailoring its band gap (direct band gap of $3.37 \mathrm{eV}$ ) with higher exciton binding energy (60 meV) as compared to other semiconductor materials such as ZnSe (22 meV), ZnS (40 meV) and GaN (25 meV) which make it suitable for short-wavelength optoelectronic devices and gas sensor applications. $^{29-32}$ Typically, $\mathrm{ZnO}$ exhibits photoluminescence characteristics in the visible and UV regions; the UV emission at $370 \mathrm{~nm}$ is due to radiative recombination of excitons while the green luminescence in $\mathrm{ZnO}$ arises due to recombination involving intrinsic defect centers such as oxygen vacancies, ${ }^{33-35}$ interstitial oxygen, ${ }^{36,37}$ zinc vacancies and interstitial zinc. ${ }^{38}$ In the present investigation, the interface between $\mathrm{ZnO}$ nanowires in the AAO creates a lot of oxygen vacancies which are responsible for strong luminescence.

The gas sensing properties of the as synthesized $\mathrm{ZnO}$ nanowire array-based gas sensors were investigated against $\mathrm{NH}_{3}$, which is highly toxic but has wide-ranging commercial applications such as in chemical industries, fertilizer factories, food processing, air conditioning equipment and refrigerators as a coolant and in the manufacture of commercial explosives (e.g., trinitrotoluene (TNT), nitroglycerin, and nitrocellulose). The natural level of $\mathrm{NH}_{3}$ in the atmosphere is about 1-5 ppb and the odor threshold is about $5 \mathrm{ppm}$. The American Conference of Governmental Industrial Hygienists (ACGIH) has assigned $\mathrm{NH}_{3}$ a threshold limit value of $25 \mathrm{ppm}$ for a normal $8 \mathrm{~h}$ work per day and a $40 \mathrm{~h}$ work per week. Therefore a system is required which can detect the presence of high as well as low concentrations of $\mathrm{NH}_{3}$ in the environment. Various $\mathrm{NH}_{3}$ sensors, including $\mathrm{ZnO}$ based sensors, have been reported so far but most of them are operated at high temperatures (up to $300{ }^{\circ} \mathrm{C}$ ) to activate the adsorption and desorption processes of $\mathrm{NH}_{3}$ which limits their use in low temperature applications. ${ }^{39-43}$ Furthermore, low power consumption is the most important requirement for gas sensors since they work day and night. Thus, to save energy and reduce the working temperature researchers are currently looking for a smart portable $\mathrm{NH}_{3}$ gas sensor with good response and recovery times that can be operated at room temperature.

In the present work, we explore the facile synthesis of a highly ordered luminescent $\mathrm{ZnO}$ nanowire array using a low temperature anodic aluminum oxide (AAO) template method. The obtained photoluminescence spectrum exhibits strong green emission peaks at 502, 457 and $490 \mathrm{~nm}$ upon excitation at a wavelength of $406 \mathrm{~nm}$ corresponding to the pristine AAO template, $\mathrm{ZnO}$ nanowires and the $\mathrm{AAO} / \mathrm{ZnO}$ assembly, respectively. Moreover, we have also investigated the fabrication as well as gas sensing mechanism, and properties including sensitivity, recovery and fast response to $\mathrm{NH}_{3}$ gas at room temperature.

\section{Experimental}

\subsection{Synthesis of ordered $\mathrm{ZnO}$ nanowire arrays}

$\mathrm{ZnO}$ nanowires of uniform size were synthesized using anodic aluminum oxide (AAO) templates. The AAO templates having ordered nanopores of 45-50 nm diameter and a thickness of $12 \mu \mathrm{m}$ were prepared and detached from Al substrates by the method reported earlier. ${ }^{44}$ After pore widening treatment in $6 \mathrm{wt} \%$ phosphoric acid solution (for $25 \mathrm{~min}$ at room temperature) the template was mounted on the porous base of a hollow cylindrical box (schematic diagram shown in Fig. 1) which was inserted into the glass tube after applying a small amount of vacuum grease. The bottom end of this glass tube was connected to a vacuum flask through a thin rubber pipe and stop cock (2). The inset of Fig. 1 shows the detached AAOtemplate supported on the razor blade. The vacuum flask in the set-up not only prevents the solution from entering the vacuum pump but also prevents air from entering the glass tube. Further, the solution level inside the glass tube can also be easily controlled with the help of a stop cock (2). After attaining the desired vacuum $\left(3-4 \times 10^{-2}\right.$ torr $)$ in the system, stopcock (1) in Fig. 1 was opened slowly to allow saturated

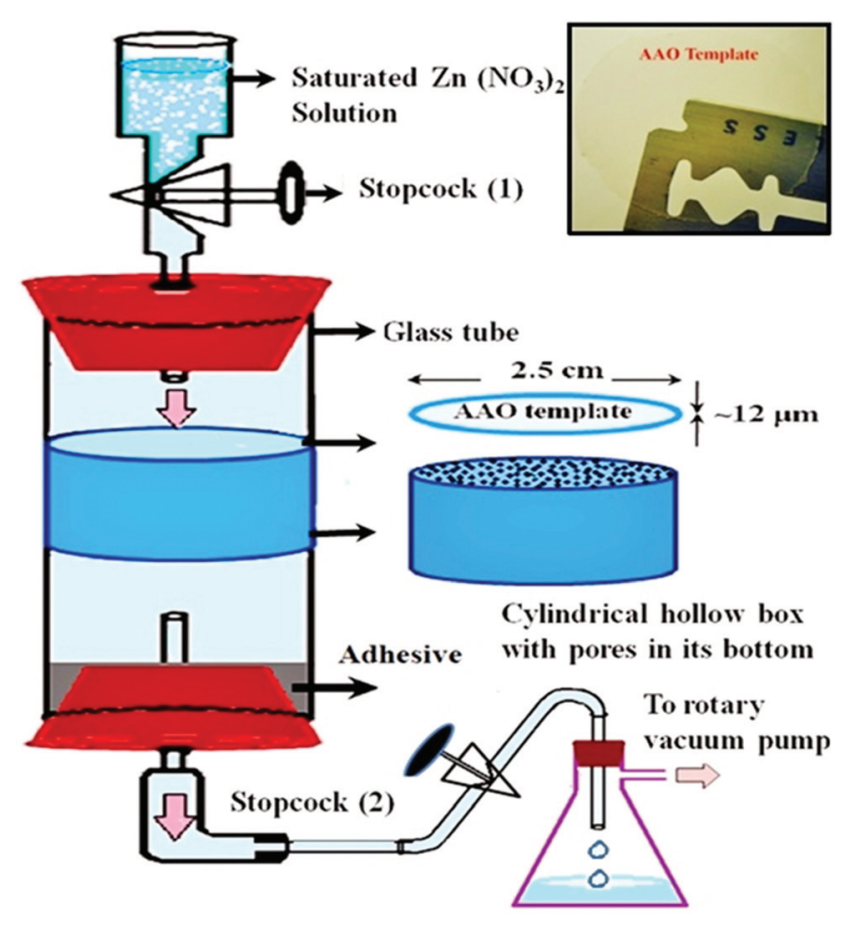

Fig. 1 Schematic diagram of the setup used for inserting solution into the pores of the AAO template. 
zinc nitrate solution to pass over the AAO-template. Stopcock (1) was closed again as soon as the solution in the container was about to finish. Due to the vacuum, some solution from the glass tube entered the vacuum flask and after that stopcock (2) was closed. It should be noted that during the whole process the template inside the tube remained dipped in the solution. Sometimes bubbles appear in the solution just above the template surface which prevents the solution from entering the pores. This problem was overcome by pushing more solution into the glass tube through stopcock (1) and the system was left under these conditions for approximately $8 \mathrm{~h}$. Later, the AAO-template was removed from the cylindrical box and kept in an electric oven at $\sim 70{ }^{\circ} \mathrm{C}$ for $6 \mathrm{~h}$. Finally, it was annealed at $435^{\circ} \mathrm{C}$ for $40 \mathrm{~h}$ to obtain wurtzite $\mathrm{ZnO}$ nanowires. In order to collect the ordered nanowires, the annealed template was thoroughly dissolved in $0.1 \mathrm{M} \mathrm{NaOH}$ solution and the floating material was collected on a razor blade. Prior to FESEM analysis this material was dried at around $70-80{ }^{\circ} \mathrm{C}$. For TEM analysis the material collected on the razor blade was dispersed in methanol and ultrasonicated for a few seconds.

The sample was characterized using a field-emission scanning electron microscope (FE-SEM, FEI QUANTA 200F) and a transmission electron microscope (TEM, Philips CM200 equipped with $\mathrm{LaB}_{6}$ filament operating at $200 \mathrm{kV}$ ). PL spectra were taken on an Edinburgh, FLSP-920, xenon flash lamp as the source of excitation.

\subsection{Fabrication of the $\mathrm{ZnO}$ nanowire array gas sensor}

In order to study the gas sensing characteristics of the as synthesized $\mathrm{ZnO}$ nanowire arrays, we fabricated a simple system of two electrodes as shown in section 3.3. Here two thin $\mathrm{Cu}$ wires were taken and the curvature at the end of each wire was reduced either by pressing or by hitting it gently. These wires were fixed on a glass plate which was covered with an insulating tape, and the gap between the two flat ends of the wires was adjusted to be less than $10 \mu \mathrm{m}$ with the help of an optical microscope. Using this technique we can make 2-3 such pairs of $\mathrm{Cu}$ wires on the same glass plate, and in the inset of figures located in section 3.3, we show a magnified "A" region of one of these glass plates. A drop of $\mathrm{ZnO}$ nanowire suspension in ethanol was placed in the gap between each pair of $\mathrm{Cu}$ wires, and an ac electric field with magnitude $15 \mathrm{Vpp}$ (peak to peak) at $0.5 \mathrm{MHz}$ was applied between points " 1 " and " 2 " as shown in section 3.3 .

\section{Results and discussion}

\subsection{FESEM and TEM studies of $\mathrm{ZnO}$ nanowires}

Fig. 2(a) exhibits the FESEM image of the filled and annealed AAO-template and the inset shows a magnified view of the "A" region. It can be seen that almost all the pores of the template are uniformly filled with the material. Fig. 2(b) shows the FESEM image of the annealed template after partially dissolving it in $0.1 \mathrm{M} \mathrm{NaOH}$ solution for $\sim 20 \mathrm{~min}$ and the inset shows the EDX profile of the same. In the image, tips of the

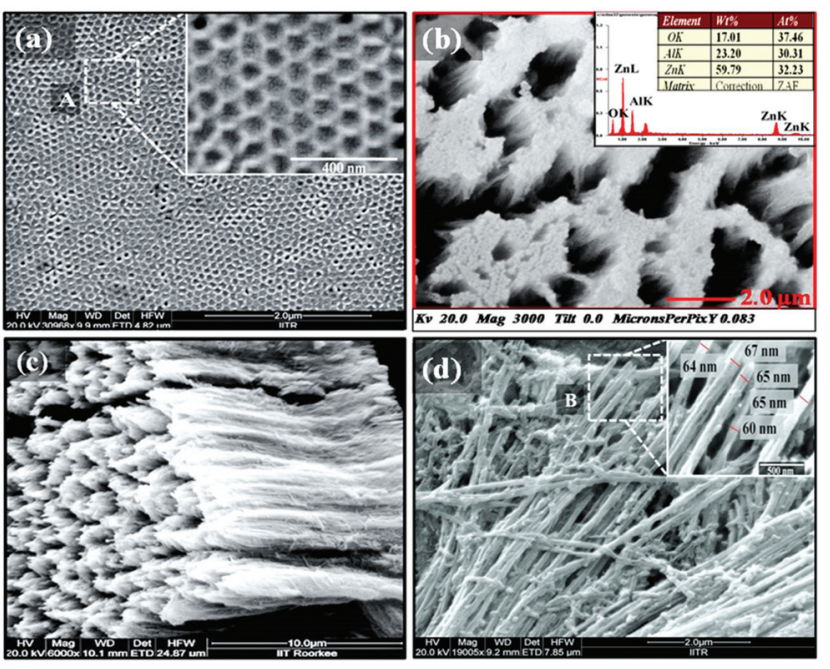

Fig. 2 (a) FESEM image, the inset shows a magnified image of the " $A$ " region of the filled and annealed AAO template, (b) FESEM image of a nanowire array after partially dissolving the filled and annealed AAO template in 0.1 M NaOH solution, the inset shows the EDX profile of the same, (c) cross-sectional FESEM image of a $\mathrm{ZnO}$ nanowire array and (d) FESEM image, the inset shows a magnified image of the " $B$ " region of ZnO nanowires.

$\mathrm{ZnO}$ nanowires embedded in the template can be clearly seen. Fig. 2(c) is the cross sectional FESEM image of a $\mathrm{ZnO}$ nanowire array after completely dissolving the alumina template in $\mathrm{NaOH}$ solution. It shows that the lengths of the nanowires are around $11 \mu \mathrm{m}$. The FESEM image shows that the $\mathrm{ZnO}$ nanowires are uniform, dense, independent and almost parallel to each other with diameters between 60 and $70 \mathrm{~nm}$ as in Fig. 2(d).

The TEM image, SAED pattern, HRTEM image and magnified HRTEM image of the as synthesized $\mathrm{ZnO}$ nanowires are shown in Fig. 3(a)-(d), respectively. In Fig. 3(a) the TEM

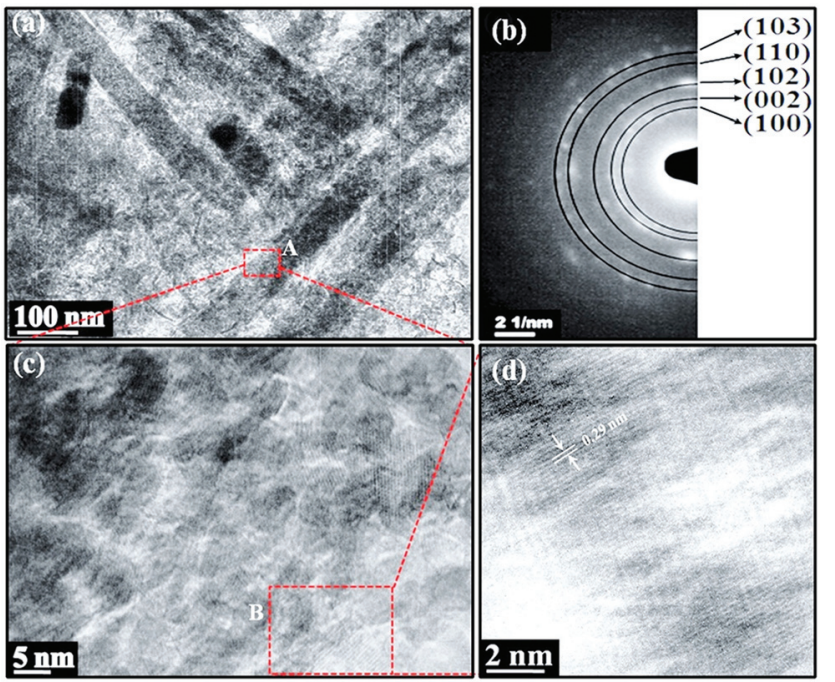

Fig. 3 (a) TEM micrograph of ZnO nanowires, (b) marked SAED pattern of $\mathrm{ZnO}$ nanowires, (c) HRTEM image of a single $\mathrm{ZnO}$ wire showing interplanar spacing and (d) magnified HRTEM image. 
micrograph shows that the nanowires have a smooth surface and an average diameter of $\sim 67 \mathrm{~nm}$. The SAED pattern in Fig. 3(b) indicates the polycrystalline nature of $\mathrm{ZnO}$ nanowires. All the polycrystalline rings observed in the SAED pattern are indexed with pure $\mathrm{ZnO}$ wurtzite phase. HRTEM in Fig. 3(c) confirms the polycrystalline nature of $\mathrm{ZnO}$ nanowires. Fig. 3(d) corresponds to a $d$-spacing value of $\sim 0.29 \mathrm{~nm}$ which corresponds to (100) planes of $\mathrm{ZnO}$ without much lattice distortion.

\subsection{Photoluminescence study of $\mathrm{ZnO}$ nanowires}

Photoluminescence (PL) is an important tool for direct optical investigation to explore electronic band structure and surface defect analysis. It can provide useful qualitative information about the interaction of free electrons on the surface of the AAO template with $\mathrm{ZnO}$ nanowires. Fig. 4(a) exhibits the excitation spectrum of the $\mathrm{AAO} / \mathrm{ZnO}$ template at $490 \mathrm{~nm}$ emission which was evaluated by a pre-scan of the $\mathrm{AAO} / \mathrm{ZnO}$ template assembly in the range of 200-900 nm. Fig. 4(b) consists of three broad strong green emission spectra peaks at 457, 502 and $490 \mathrm{~nm}$ upon excitation at a wavelength of $406 \mathrm{~nm}$ corresponding to $\mathrm{ZnO}$ nanowires, the pristine AAO template and the $\mathrm{AAO} / \mathrm{ZnO}$ assembly which are represented by curves 1, 2 and 3, respectively. Here, the emission spectrum of $\mathrm{ZnO}$ nanowires (curve 1) was obtained after subtracting curve 2 from curve 3 and the intensity of $\mathrm{ZnO}$ nanowire emission spectra (curve 1) was found to be 2.5 times lower than that of the $\mathrm{AAO} / \mathrm{ZnO}$ assembly (curve 3). The origin of the defect related electronhole recombination process in $\mathrm{ZnO}$ nanowires has been extensively investigated; however, it remains debatable. Among the different mechanisms proposed to explain the visible luminance in $\mathrm{ZnO}$ nanowires to date, oxygen vacancies have been widely accepted as the most probable candidate. ${ }^{45}$ In the present investigation, we have used the AAO template for synthesis of aligned $\mathrm{ZnO}$ nanowires which introduced intrinsic defects on the surface of $\mathrm{ZnO}$ nanowires in order to enhance the strong green emission compared to pristine AAO as well as $\mathrm{ZnO}$ as shown in Fig. 4(b). ${ }^{46}$ The broad emission peaks in the spectra are the consequence of different types of defects existing in the samples. We proposed that AAO plays a key role in enhancing the green emission in the AAO/ZnO hybrid structure. The strong interface formed during synthesis of $\mathrm{ZnO}$
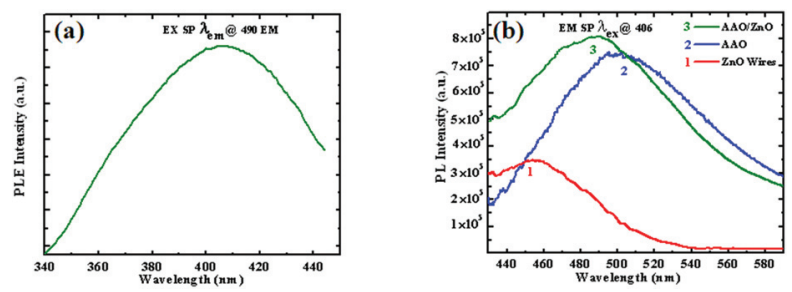

Fig. 4 (a) The photoluminescence excitation spectra (PLE) of the AAO/ $\mathrm{ZnO}$ assembly, (b) three broad strong green emission spectra peaking at 457, 502 and $490 \mathrm{~nm}$ upon excitation at a wavelength of $406 \mathrm{~nm}$ corresponding to $\mathrm{ZnO}$ nanowires, the pristine $\mathrm{AAO}$ template, and the $\mathrm{AAO} / \mathrm{ZnO}$ assembly which are represented by curves 1, 2 and 3 respectively. nanowires on the AAO template, which creates higher defect densities in $\mathrm{ZnO}$, gives rise to higher PL intensity in comparison to pristine $\mathrm{ZnO}$ and pristine AAO.

The other probable reason behind the strong luminescence in $\mathrm{AAO} / \mathrm{ZnO}$ may be the higher interfacial area provided by $\mathrm{ZnO}$ nanowires to AAO. A higher surface to volume ratio leads to a higher concentration of defects induced by the AAO-template on the $\mathrm{ZnO}$ nanowire surface; as a result $\mathrm{V}_{\mathrm{o}}^{+}$from the $\mathrm{ZnO}$ surface and free electrons from AAO recombine strongly as compared to pristine $\mathrm{ZnO}$ to produce strong green emission.

\section{3. $\quad V-I$ characteristics of nanowires}

When an ac electric field with magnitude $15 \mathrm{Vpp}$ (peak to peak) at $0.5 \mathrm{MHz}$ was applied between points " 1 " and " 2 " (Fig. 5(a)) (after placing a drop of suspension in the gap between the electrodes), electric field $(E)$ induces charge separation and the resulting polarization develops a dipole moment which aligns the nanowires parallel to the field lines. In the case of non-uniform field distribution, the alignment force or the dielectrophoretic force $\left(F \propto \nabla|E|^{2}\right.$ where $\nabla$ is the gradient vector operator) moves the polarized structure towards the region of highest field density. ${ }^{47} \mathrm{~A} \mathrm{ZnO}$ nanowire array trapped between the two $\mathrm{Cu}$ electrodes due to this dielectrophoresis process is shown in Fig. 5(b).

The $V-I$ characteristics of the $\mathrm{ZnO}$ nanowire array trapped between the electrodes (Fig. 5(b)) are shown in Fig. 6(a).

A Cu-ZnO nanowire array, which is basically a metal-semiconductor-metal (MSM) structure, shows almost symmetric characteristics. Such MSM structures can be considered as being composed of two Schottky barriers connected back to back in series with a semiconducting material. If a barrier at both ends of the nanowire array possesses similar good quality contacts with approximately lower barrier heights, then symmetric characteristics are obtained. ${ }^{48}$ The resistance of the nanowire array is of the order of $6 \mathrm{G} \Omega$ at $1 \mathrm{~V}$, which includes contact resistance as well. Such high resistivity is due to $\mathrm{ZnO}$ being a wide bandgap semiconductor $\left(E_{\mathrm{g}}=3.3 \mathrm{eV}\right)$ at room temperature. $^{49}$

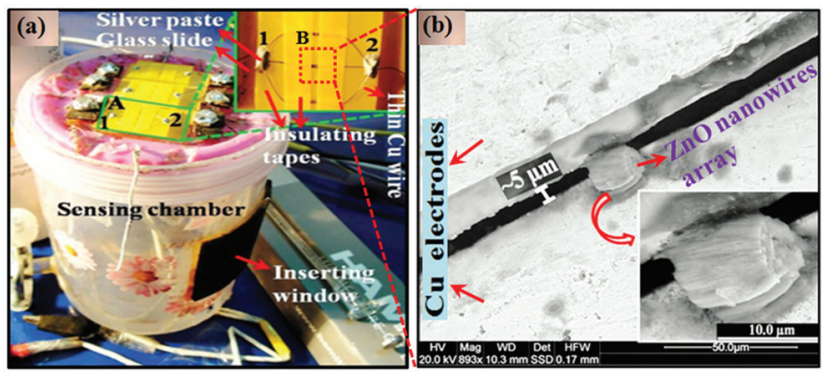

Fig. 5 (a) Schematic diagram of the chamber used for gas sensing measurements, the inset shows the magnified " $A$ " region of one of the glass plates which consists of 3 pairs of $\mathrm{Cu}$ electrodes and (b) magnified FESEM image of the " $B$ " region which shows a nanowire array kept between the two electrodes. 

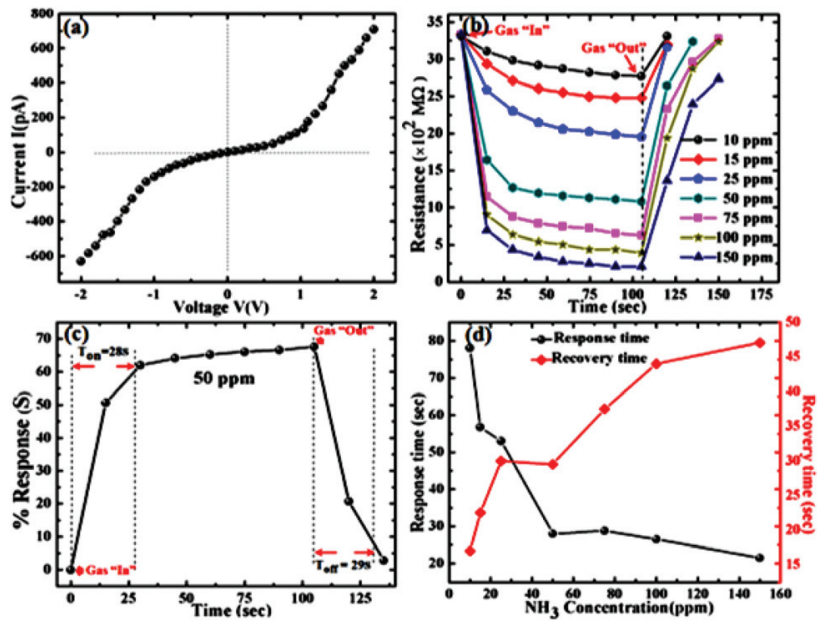

Fig. 6 (a) $V-I$ curve of a $\mathrm{ZnO}$ nanowire array kept between the two electrodes, (b) variation in the resistance of a $\mathrm{ZnO}$ nanowire array with time when exposed to different concentrations of $\mathrm{NH}_{3}$ at room temperature, (c) response curve of the sensor for $50 \mathrm{ppm} \mathrm{NH}$ and the curve is utilized to calculate the response and recovery times and (d) response and recovery times of the sensor with respect to the $\mathrm{NH}_{3}$ concentration.

\subsection{Gas sensing properties of nanowires}

For investigating room temperature gas sensing properties of the trapped $\mathrm{ZnO}$ nanowire array, the sensor was kept in an airtight box (volume $500 \mathrm{~cm}^{3}$ ). $1000 \mathrm{ppm} \mathrm{NH}_{3}$ (Chemtron Science Laboratories Pvt. Ltd, India) was used as the test gas, and using the relation (capacity of syringe used $\times$ ppm level mentioned on canister $=$ capacity of sensing container $\times$ required ppm level) different quantities of 1000 ppm $\mathrm{NH}_{3}$ were inserted into the airtight sensing box through the inserting window using a micro-syringe so as to yield the desired ppm concentration of $\mathrm{NH}_{3}$. A fixed bias of $0.1 \mathrm{~V}$ was applied across the electrodes (points " 1 " and " 2 " in Fig. 5(a)) and the change in the resistance of the sensor was measured using a picoammeter. Before starting the measurement for every next $\mathrm{NH}_{3}$ concentration, the test gas in the sensing chamber was pumped out using a vacuum pump so that the sensor recovered its initial resistance value. Fig. 6(b) shows the response and recovery curves (in terms of resistance) of the $\mathrm{ZnO}$ nanowire array upon exposure to 10, 15, 25, 50, 75, 100 and $150 \mathrm{ppm} \mathrm{NH}_{3}$ at room temperature. These curves show that the change in the resistance sensibly depends on the $\mathrm{NH}_{3}$ concentration and it increases with an increase in the value of $\mathrm{NH}_{3}$ concentration. The \% response $(S)$ of this sensor for $50 \mathrm{ppm} \mathrm{NH} \mathrm{NH}_{3}$ is shown in Fig. 6(c). The \% response $(S)$ of a sensor is defined as $\left|\left(R_{\mathrm{a}}-R_{\mathrm{g}}\right) / R_{\mathrm{a}}\right| \times 100$, where $R_{\mathrm{a}}$ and $R_{\mathrm{g}}$ are resistances of the sensor in air and gas, respectively. Fig. 6(c) shows that the response and recovery times (defined as the time required to reach $90 \%$ of the saturation value) of the sensor when exposed to $50 \mathrm{ppm} \mathrm{NH}_{3}$ concentration are $\sim 28 \mathrm{~s}$ and $\sim 29 \mathrm{~s}$, respectively. The response time of the sensor decreases with an increase in the gas concentration while the recovery time increases with an increase in the gas concentration. This behavior of the sensor is shown in Fig. 6(d).
$\mathrm{NH}_{3}$ concentration versus \% response of the sensor is shown in Fig. 7. It can be seen that the \% response increases almost linearly with increase in $\mathrm{NH}_{3}$ concentration up to $75 \mathrm{ppm}$, and above $75 \mathrm{ppm}$ the \% response increases slowly with the increase in $\mathrm{NH}_{3}$ concentration.

The linear response of the sensor up to $75 \mathrm{ppm}$ shows a power law dependence of the \% response $(S)$ on the gas concentration $(C)$, i.e., $S=A C^{\alpha}$, where $A$ is a constant. ${ }^{50,51}$ The reason behind the power law dependence is associated with the interaction or adsorption of $\mathrm{NH}_{3}$ molecules on the sensing surface and with the change of surface potential. The power law fit to the linear portion of the response $(S)$ and concentration $(C)$ curve is shown in the inset of Fig. 7. The fitting data reveal that the value of $\alpha$ is about 0.75 which is in agreement with the predictions of the rational value $(1$ or $1 / 2)$ for the power law exponent.

Most metal-oxide-semiconductor gas sensors work on the principle of a change in the conductance of the sensing materials due to the interaction between the gas species and the adsorbed oxygen ions $\left(\mathrm{O}_{2}{ }^{-}, \mathrm{O}^{-}\right.$and $\left.\mathrm{O}^{2-}\right)$. Initially, when a $\mathrm{ZnO}$ nanowire sensor is placed in an open atmosphere, the adsorbed oxygen ions $\left(\mathrm{O}_{2}{ }^{-}, \mathrm{O}^{-}\right.$and $\left.\mathrm{O}^{2-}\right)$ extract electrons from the conduction band forming a depletion region which reduces the conducting width of $\mathrm{ZnO}$ wires and increases the potential barrier of the contacts between the nanowires and hence increases the resistance of the sensor. The nature and concentration of chemisorbed oxygen species strongly depend on temperature. $\mathrm{O}_{2}{ }^{-}$is commonly chemisorbed at lower temperatures $\left(<100{ }^{\circ} \mathrm{C}\right)$. At higher temperatures $\mathrm{O}^{-}$and $\mathrm{O}^{2-}$ are usually chemisorbed while $\mathrm{O}_{2}{ }^{-}$disappears rapidly. ${ }^{52}$ On exposure to $\mathrm{NH}_{3}$ at room temperature, $\mathrm{O}_{2}{ }^{-}$species at the sensor surface interact with $\mathrm{NH}_{3}$ resulting in release of electrons. The reaction kinetics can be described as follows:

$$
\mathrm{O}_{2}(\text { gas }) \rightarrow \mathrm{O}_{2}(\text { ads })
$$

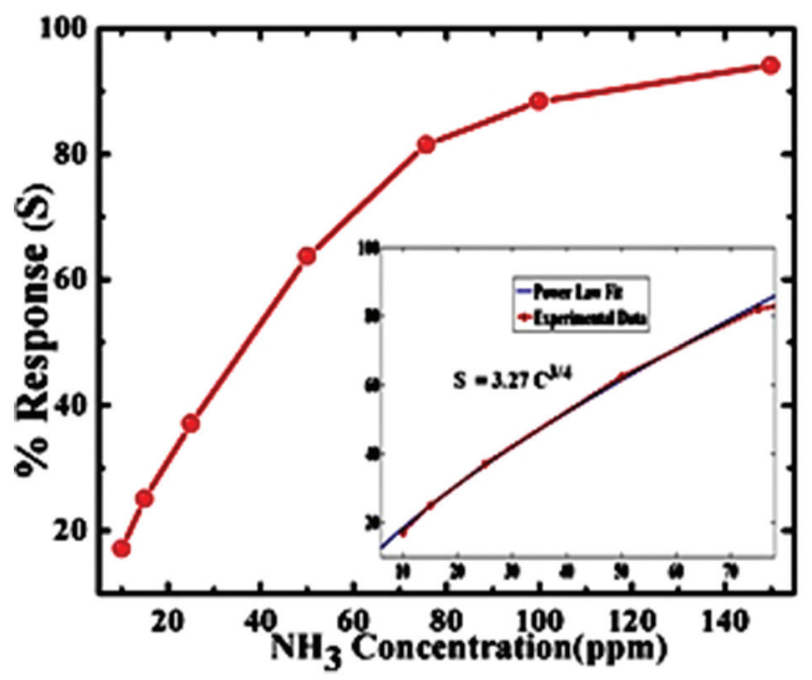

Fig. $7 \mathrm{NH}_{3}$ concentration vs. response and the inset shows the power law fit to the linear portion of the curve. 


$$
\begin{gathered}
\mathrm{O}_{2}(\text { ads })+\mathrm{e}^{-} \rightarrow \mathrm{O}_{2}^{-}(\text {ads }) \\
4 \mathrm{NH}_{3}+5 \mathrm{O}_{2}{ }^{-} \rightarrow 6 \mathrm{H}_{2} \mathrm{O}+4 \mathrm{NO}+5 \mathrm{e}^{-}
\end{gathered}
$$

Thus, the trapped electrons are released back into the $\mathrm{ZnO}$ conduction band leading to an increase in the carrier concentration of the $\mathrm{ZnO}$ active layer. Thus the sensor resistance decreases upon exposure to $\mathrm{NH}_{3}$ gas, as shown in Fig. 6(b).

The sensing properties of a sensor greatly depend upon the microstructural features of the sensing material, such as geometry, aspect-ratio and the connectivity among the nanostructures (wires, grains etc.). The sensing material in this sensor are $\mathrm{ZnO}$ nanowires which are vertically aligned and in contact with each other. These nanowires are in the form of a bundle and almost parallel to the gap between the electrodes. For $\mathrm{ZnO}$ wires in air the Debye length (the distance over which a local electric field affects the distribution of free charge carriers) is $30 \mathrm{~nm}$ which is comparable to the radius of our synthesized $\mathrm{ZnO}$ nanowires $(\sim 34 \mathrm{~nm}) .{ }^{53,54}$ This implies that the nanowire is almost depleted and the surface depletion will greatly influence the density and mobility of the electrons in the nanowire. The sensing mechanism of an individual $\mathrm{ZnO}$ nanowire is shown in Fig. 8.

Since here Debye length is comparable to the radius of the nanowire, in an air environment the adsorption of oxygen species (electron acceptor) on the surface of the nanowire shifts the Fermi level away from the conduction band whereas in an $\mathrm{NH}_{3}$ environment due to the presence of oxygen vacancies the $\mathrm{ZnO}$ nanowire behaves as an n-type semiconductor. In a nanowire array, the nanowires are in contact with each other; therefore the depletion layer will effectively modify the potential barrier at contact between the wires. On considering the above facts and using a neck-grain boundary control model, total resistance $(R)$ of the nanowire array can be written as $^{54,55}$

$$
R=R_{\mathrm{N}}+R_{\mathrm{C}}
$$

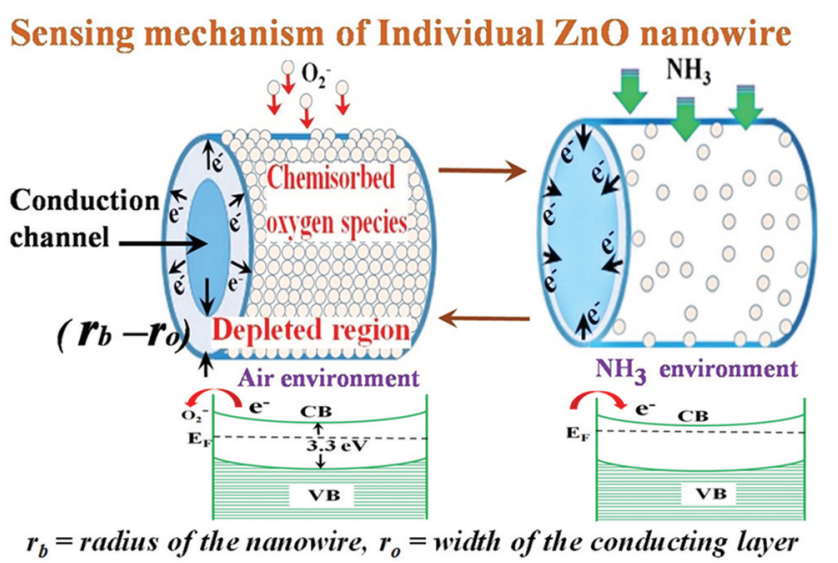

Fig. 8 Sensing mechanism of an individual $\mathrm{ZnO}$ nanowire and energy level diagrams of the wire in air as well as in an $\mathrm{NH}_{3}$ environment. where $R_{\mathrm{N}}$ is the bulk resistance of the $\mathrm{ZnO}$ nanowire array and $R_{\mathrm{C}}$ is the contact resistance. On substituting the values of $R_{\mathrm{N}}$ and $R_{\mathrm{C}}$ in eqn (4), total resistance is

$$
R=\frac{L}{n \pi e\left[\mu_{\mathrm{b}} n_{\mathrm{b}} r_{0}^{2}+n_{\mathrm{d}} \mu_{\mathrm{d}}\left(r_{\mathrm{b}}^{2}-r_{0}^{2}\right)\right]}+R_{0} \exp \left\{-\frac{e \Delta V_{\mathrm{b}}}{k_{\mathrm{B}} T}\right\}
$$

where $L$ is the length of nanowires, $n$ is the number of parallel $\mathrm{ZnO}$ nanowires in the array, $e$ is the charge of the electron, $\mu_{\mathrm{b}}$ is the electron mobility in the neutral layer, $\mu_{\mathrm{d}}$ is the electron mobility in the depleted region, $n_{\mathrm{b}}$ is the free electron density in the nanowire, $n_{\mathrm{d}}$ is the free electron density in the depleted region, $r_{0}$ is the width of the conducting layer, $r_{\mathrm{b}}$ is the radius of the nanowire, $R_{0}$ is a constant term which depends on air resistance and other parameters, $k_{\mathrm{B}}$ is Boltzmann's constant, $T$ is the absolute temperature and $\Delta V_{\mathrm{b}}$ is the change in contact potential barrier, i.e. potential in air minus that in ammonia.

The contact resistance of the $\mathrm{ZnO}$ nanowires is controlled by the interwire barriers at the contact and this potential barrier is the key factor in controlling the total resistance of the sensor $(R)$ and thus influences the transport of electrons between the wires. When the sensor is exposed to $\mathrm{NH}_{3}$, due to the exchange of charge carriers between ammonia molecules and the adsorbed oxygen species the depletion width decreases. This will cause a decrease in barrier potential width and height at the contacts. Thus $\Delta V_{\mathrm{b}}$ increases and the total resistance $(R)$ of the nanowire sensor decreases. The \% response of a sensor depends on the change in resistance $(\Delta R)$ upon exposure to the test gas. On increasing the gas concentration, $\Delta V_{\mathrm{b}}$ increases and as a consequence sensor resistance decreases and hence the response of the sensor increases. On increasing $\mathrm{NH}_{3}$ concentrations continuously, the contact potential barrier $\Delta V_{\mathrm{b}}$ rapidly decreases and the slope of the response curve decreases with it (Fig. 7). The reason behind this is the decreased possibility of charge sharing between the ammonia and adsorbed oxygen due to a reduction in the concentration of adsorbed oxygen species at the surface of the nanowire. ${ }^{56}$ Thus the sensor saturates at higher concentrations as shown in Fig. 7.

The bi-functional optical and gas sensing properties of this material create new avenues for optoelectronic and gas sensing applications.

\section{Conclusion}

In summary, we have successfully synthesized luminescent ZnO nanowires and fabricated a gas sensor by a simple cost effective technique in which empty pores of the commercial AAO-template were filled with the material by the vacuum sucking technique. The photoluminescence spectrum reveals that the $\mathrm{AAO} / \mathrm{ZnO}$ assembly has a strong green emission peaking at $490 \mathrm{~nm}$ upon excitation at a wavelength of $406 \mathrm{~nm}$. The AAO/ZnO has higher luminescence intensity compared to pristine $\mathrm{ZnO}$ due to its high surface to volume ratio. In order to study the sensing characteristics of the as synthesized nanowire array, a simple sensing system was developed using a 
micromechanical technique. The sensor shows good response to an $\mathrm{NH}_{3}$ atmosphere at room temperature. We believe that these simple and cost effective techniques can be extended to synthesize nanowire arrays of other metal/metal oxides too and may be helpful in studying their sensing properties towards various gases at room temperature.

\section{Acknowledgements}

The authors are grateful to Dr S. K. Gupta (B.A.R.C.) for helpful discussions. The financial support from BRNS (DAE) is highly acknowledged. Mr Nagesh Kumar acknowledges the financial support from CSIR, New Delhi, India, under a Senior Research Fellowship (2012-13).

\section{Notes and references}

1 R. Kumar and N. Khare, Thin Solid Films, 2008, 516, 1302-1307.

2 H. Yan, J. Johnson, M. Law, R. He, K. Knutsen, J. R. McKinney, J. Pham, R. Saykally and P. Yang, Adv. Mater., 2003, 15, 907-910.

3 J. Singh, S. S. Patil, M. A. More, D. S. Joag, R. S. Tiwari and O. N. Srivastava, Appl. Surf. Sci., 2010, 256, 6157-6163.

4 T. Yu, F.-C. Cheong and C.-H. Sow, Nanotechnology, 2004, 15, 1732-1736.

5 Y. Li, P.-C. Hsu and S.-M. Chen, Sens. Actuators, B, 2012, 174, 427-435.

6 G. Shin, M. Y. Bae, H. J. Lee, S. K. Hong, C. H. Yoon, G. Zi, J. A. Rogers and J. S. Ha, ACS Nano, 2011, 5(12), 1000910016.

7 L. Guo, E. Leobandung and S. Y. Chou, Appl. Phys. Lett., 1997, 70, 850.

8 R. Cooper, H. P. Upadhyaya, T. K. Minton, M. R. Berman, X. Du and S. M. George, Thin Solid Films, 2008, 516, 40364039.

9 S. Raghu, S. B. Chung and S. Lederer, J. Phys.: Conf. Ser., 2013, 449, 012031.

10 W. Oelerich, T. Klassen and R. Bormann, J. Alloys Compd., 2001, 315, 237-242.

11 (a) C. Wang, L. Yin, L. Zhang, D. Xiang and R. Gao, Sensors, 2010, 10, 2088-2106; (b) G. Korotcenkov, Mater. Sci. Eng., B, 2007, 139, 1-23.

12 V. Balouria, S. Samanta, A. Singh, A. K. Debnatha, A. Mahajan, R. K. Bedi, D. K. Aswal and S. K. Gupta, Sens. Actuators, B, 2013, 176, 38-45.

13 V. Srikant and D. R. Clarke, J. Appl. Phys., 1998, 83.

14 F. M. Li, G. W. Hsieh, S. Dalal, M. C. Newton, J. E. Stott, P. Hiralal, A. Nathan, P. A. Warburton, H. E. Unalan, P. Beecher, A. J. Flewitt, I. Robinson, G. Amaratunga and W. I. Milne, IEEE Trans. Electron Devices, 2008, 55, 3001.

15 Y. Dan, Y. Cao, T. E. Mallouk, S. Evoy and A. T. C. Johnson, Nanotechnology, 2009, 20, 434014-4.
16 M. Yun, C. Lee, R. P. Vasquez, R. Penner, M. Bangar, A. Mulchandani and N. V. Myung, Proc. SPIE-Int. Soc. Opt. Eng., 2004, 5593, 200-206.

17 R. A. Michaels, Environ. Health Perspect., 1999, 107, 617-627.

18 P. G. Su, C. T. Lee, C. Y. Chou, K. H. Cheng and Y. S. Chuang, Sens. Actuators, B, 2009, 139, 488-493.

19 X. Wang, C. J. Summers and Z. L. Wang, Nano Lett., 2004, 4, 423-426.

20 L. E. Greene, M. Law, J. Goldberger, F. Kim, J. C. Johnson, Y. Zhang, R. J. Saykally and P. Yang, Angew. Chem., Int. Ed., 2003, 42, 3031-3034.

21 W. Z. Liu, H. Y. Xu, L. Wang, X. H. Li and Y. C. Liu, AIP Adv., 2011, 1, 022145-8.

22 L. Vayssieres, Adv. Mater., 2003, 15, 464-466.

23 P. Wu, H. Zhang, Y. Qian, Y. Hu, H. Zhang and C. Cai, J. Phys. Chem. C, 2013, 117, 19091-19100.

24 X. Zhao, Y. Wu and X. Hao, Int. J. Electrochem. Sci., 2013, 8, 1903-1910.

25 X. T. Hoang, D. T. Nguyen, B. C. Dong and H. N. Nguyen, Adv. Nat. Sci.: Nanosci. Nanotechnol., 2013, 4, 035013.

26 M. A. Zeeshan, S. Pane, S. K. Youn, E. Pellicer, S. Schuerle, J. Sort, S. Fusco, A. M. Lindo, H. G. Park and B. J. Nelson, Adv. Funct. Mater., 2013, 23, 823-831.

27 F. I. Dar, K. R. Moonooswamy and M. Es-Souni, Nanoscale Res. Lett., 2013, 8, 363.

28 X. Zhao, G. Meng, F. Han, X. Li, B. Chen, Q. Xu, X. Zhu, Z. Chu, M. Kong and Q. Huang, Sci. Rep., 2013, 3, 2238.

29 N. S. Ramgir, Y. Yang and M. Zacharias, Small, 2010, 6, 1705-1722.

30 C. S. Rout, S. H. Krishna, S. R. C. Vivek chand, A. Govindaraj and C. N. R. Rao, Chem. Phys. Lett., 2006, 418, 586-590.

31 M. H. Huang, S. Mao, H. Feick, H. Q. Yan, Y. Y. Wu, H. Kind, E. Weber, R. Russo and P. Yang, Science, 2001, 292, 1897-1899.

32 N. Riehl and O. Z. Ortman, Electrochemistry, 1952, 60, 149.

33 P. H. Kasai, Phys. Rev., 1963, 130, 989.

34 F. A. Kroger and H. J. Vink, J. Chem. Phys., 1954, 22, 250.

35 I. Y. Prosanov and A. A. Politov, Inorg. Mater., 1995, 31, 663.

36 D. Hahn and R. Nink, Phys. Condens. Matter, 1965, 3, 311.

37 M. Liu, A. H. Kitai and P. J. Mascher, Lumin., 1992, 54, 35.

38 E. G. Bylander, J. Appl. Phys., 1978, 49, 1188.

39 C. S. Rout, M. Hegde, A. Govindaraj and C. N. R. Rao, Nanotechnology, 2007, 18, 2055041-2055049.

40 D. R. Patil and L. A. Patil, IEEE Sens. J., 2007, 7, 434-439.

41 B. Timmer, W. Olthuis and A. van den Berg, Sens. Actuators, $B, 2005,107,666-677$.

42 M. S. Wagh, G. H. Jain, D. R. Patil, S. A. Patil and L. A. Patil, Sensors and Actuators, B, 2006, 115, 128-133.

43 B. Karunagaran, P. Uthirakumar, S. J. Chung, S. Velumani and E.-K. Suh, Mater. Charact., 2007, 58, 680-684.

44 N. Kumar, G. D. Varma, R. Nath and A. K. Srivastava, Appl. Phys. A, 2011, 104, 1169-1174.

45 B. K. Gupta, V. Grover, G. Gupta and V. Shanker, Nanotechnology, 2010, 21, 475701. 
46 M. Wu, L. Yao, W. Cai, G. Jiang, X. Li and Z. Yao, J. Mater. Sci. Technol., 2004, 10, 11-13.

47 H. A. Pohl, J. Appl. Phys., 1951, 22, 869-863.

48 D. Q. Wang, R. Zhu, Z. Y. Zhou and X. Y. Ye, Chin. Phys. B, 2008, 17, 3875-3879.

49 V. Srikant and D. R. Clarke, J. Appl. Phys., 1998, 83, 5447-5445.

50 N. S. Ramgir, M. Ghosh, P. Veerender, N. Datta, M. Kaur, D. K. Aswal and S. K. Gupta, Sens. Actuators, B, 2011, 156, 875-880.

51 N. Yamazoe and K. Shimanoe, Sens. Actuators, B, 2008, 128, 566-573.
52 J. C. Belmonte, J. Manzano, J. Arbiol, A. Cirera, J. Puigcorbe, A. Vila, N. Sabate, I. Gracia, C. Cane and J. R. Morante, Sens. Actuators, B, 2006, 114, 881-892.

53 O. Lupan, L. Chow, T. Pauporte, L. K. Onoa, B. Roldan Cuenya and G. Chai, Sens. Actuators, B, 2012, 173, 772780.

54 Z. Yang, L. M. Li, Q. Wan, Q. H. Liu and T. H. Wang, Sens. Actuators, B, 2008, 135, 57-60.

55 Y. Mas, W. L. Wang, K. J. Liao and C. Y. Kong, J. Wide Bandgap Mater., 2002, 10, 113-119.

56 P. Feng, Q. Wan and T. H. Wang, Appl. Phys. Lett., 2005, 87, 213111-3. 